in the course of twenty weeks these ran 4,200 miles and carried 12,761 passengers. Both the papers contained much information on the construction of these and other early steam omnibuses and it cannot be doubted that if the inventions had been fostered, instead of hindered, by legislation, the steam vehicle would have been brought to a high degree of perfection at an early date.

\section{Observational and Theoretical Astronomy}

ON April 28, Prof. H. H. Plaskett delivered his inaugural lecture as Savilian professor of astronomy at Oxford. Recalling the fact that the year of the foundation of the professorship was also that of the publication of Kepler's three laws of planetary motion, and directing attention to the injunction of Sir Henry Savile that the holder of his professorship should occupy himself with "observation by day and night", he remarked that three hundred years ago the observational method in astronomy might be said to have reached its zenith. Since then, the constantly increasing importance of the theoretical method has been abundantly shown; as, for example, in the discovery of Neptune by calculation and in the present conclusions as to the physical conditions in the interior of stars. Nevertheless, the achievements of theoretical astronomy still rest in part on an observational basis. This is shown by consideration of the means by which knowledge of the spatial distribution of the stars has been gained by the work of Herschel and Shapley, and of that of their physical constitution by the work of Lockyer, Franklin and Hertzsprung. It would be fair to say, looking forward to the next three or four hundred years, that it will be allowed that, so far, observation and theory have gone along hand in hand. In a more distant future it may not be so. At present, theory has played its part in the refinement of observation, but some of the results of theory must for ever be removed from observational control. But just as the explorer of the earth's surface suggests to the geographer plans for further fruitful exploration, so the astronomer going to Nature with a definite theory may succeed in getting an answer. Finally, there can be no doubt that a great university should have an observatory as part of its equipment; but it must be recognised that the part of astronomy under these conditions necessarily has its limitations.

\section{Lachish}

Excavations at Tell Duweir in Palestine, where the Wellcome Historical Museum Expedition has been at work under Mr. J. L. Starkey, have now closed for the season. The particular interest of this excavation lies in the possibility that the site may be the city of Lachish which was captured by Joshua after a stout resistance. So far, nothing has been found to contradict this tentative identification, while some of the evidence from this season's work tends to confirm it. Lachish was captured by Sennacherib in 701 B.c.--this siege is represented on bas-reliefs from Nineveh now in the British Museum - and by Nebuchadnezzar in 586 B.c. Tell Duweir, which is situated about twenty-five miles south-west of Jerusalem at a height of $900 \mathrm{ft}$. above sea-level, dominating the Philistine country, is a mound of some forty acres in extent, tapering to eighteen acres at the summit. The stone walls identified with the city of Rehoboam show the breaches made by Sennacherib's army and traces of the conflagration by which they were made to collapse under Nebuchadnezzar. Under the stone walls of Rehoboam's city were found the red brick walls which are identified with the city of Joshua's day. A further piece of evidence pointing in the direction of the identification is the find of a metal helmet crest which corresponds with the crests on the peculiarly shaped helmets of some of Sennacherib's soldiers shown on the British Museum bas-reliefs. Part of a royal palace on the summit of the mound was uncovered, and a number of graves at the base belonging to all ages were examined and yielded a large number of skulls in excellent preservation. Objects from Tell Duweir will be on exhibition at the Wellcome Historical Museum, Euston Road, London, N.W.1, on their early arrival in England.

\section{National Research Council of Canada}

THE National Research Council of Canada has issued a statement covering its sixteen years work which indicates a close parallel between the activities of this Council and those of the Department of Scientific and Industrial Research in Great Britain. In addition to the direction of a wide range of investigations in a National Research Laboratories system, the development of a national library of science, and the publication of a Canadian Journal of Research, the Council has developed co-operation in research throughout Canada, instituted a policy of grants to individual research workers, and assisted in the training of scientific personnel by the award of scholarships to selected students and graduates. Its efforts have raised the whole standard of research in Canada and in addition the National Research Council has already proved its value in the day-today problems of government and to various State departments. During the sixteen years of its existence, the Council has paid a total of $527,951,000$ dollars in research scholarships and 131,801,292 dollars in grants for research. More than half of the total expenditure has been incurred on the building and organisation of the National Research Laboratories, which were formally opened on August 10, 1932, and have already made notable contributions to scientific knowledge and industrial development.

From a summarised account of these activities occupying nearly fifty pages, it is only possible to select a few points as illustrations. Important contributions to the asbestos industry have been rendered by investigations on asbestos cements and the standardisation of testing and methods. Studies of the resistance of concrete structures, the development of a highly resistant cement, of the treatment and disposal of sulphur dioxide fumes from smelter stacks, waste gas and bitumen utilisation, on the 